\title{
Composites
}

\section{Influence of filler/matrix interactions on resin/hardener stoichiometry, molecular dynamics, and particle dispersion of silicon nitride/epoxy nanocomposites}

\author{
Fuad N. Alhabill ${ }^{1, *}$ (D, Raed Ayoob ${ }^{1}$, Thomas Andritsch ${ }^{1}$, and Alun S. Vaughan ${ }^{1}$ \\ ${ }^{1}$ The Tony Davies High Voltage Laboratory, School of Electronics and Computer Science, University of Southampton, \\ Southampton SO17 1BJ, UK
}

Received: 30 August 2017

Accepted: 15 November 2017

Published online:

20 November 2017

(C) The Author(s) 2017. This article is an open access publication

\begin{abstract}
The addition of nanofillers can have a significant influence on the resin stoichiometry of thermosetting polymer systems. Based on differential scanning calorimetry (DSC) results, it is estimated that the inclusion of 2 and $5 \mathrm{wt} \%$ of silicon nitride nanofiller displaces the resin/hardener stoichiometry of an epoxy/amine network by 6.5 and $18 \%$, respectively. Dielectric spectroscopy results confirm the above findings, in that the spectra of the nanocomposite samples were found to be equivalent to the spectra of unfilled samples when the above stoichiometric effect was taken into account. Therefore, this study provides clear evidence that the presence of a nanofiller can directly and significantly affect the curing process of an epoxy network. Consequently, this should always be considered when introducing nanofillers into thermosetting matrices. These results indicate the presence of covalent bonding between the nanoparticles and the surrounding polymer and, therefore, provide an opportunity to explore the influence of this bonding on the molecular dynamics of the polymer layer around the particles. However, the obtained DSC and dielectric spectroscopy results suggest that, in the system considered here, either the covalent bonding does not have an appreciable influence on the segmental dynamics of the polymer, as revealed by these techniques, or that the thickness of the affected layer is less than $1 \mathrm{~nm}$ and therefore too small to be distinguished from experimental uncertainties.
\end{abstract}

\section{Introduction}

Over the last decade, nanodielectrics has captured the attention of many researchers worldwide in their search to develop new high-voltage (HV) insulation materials that meet the steadily growing demand for increased energy density and lower loss electrical power systems. However, a detailed and critical understanding of the linkage between the physics and chemistry of the components of nanodielectrics

Address correspondence to E-mail: fna1g13@soton.ac.uk 
(nanofiller and polymer matrix) and the electrical behaviour of these systems are far from being secured yet. One of the key aspects of a nanofiller is its large specific surface area, which will result in a large interfacial area between the nanofiller and the encapsulating polymer. Different chemical [1], physical [2] or electrical [3] interactions can occur between the two phases, depending on the characteristics of the matrix and the nanofiller. For epoxy-based nanocomposites, nanoparticles are incorporated into the resin in its liquid state before the curing process, which allows better particle dispersion and also enables the particles to interact with the reactive resin and hardener. These interactions might include chemical reactions between the nanofiller surface functionalities and the active groups, either in the resin (e.g. epoxy groups) or in the hardener (e.g. the amine groups in the current study). Such reactions may modify the effective resin/hardener stoichiometry and, thereby, change the structure of the resulting network after curing. A previous investigation [4] showed that modifying the resin/hardener stoichiometry in an unfilled epoxy system significantly influences the electrical properties of the resulting epoxy network. Accordingly, the influence of nanofiller addition into an epoxy matrix might be related to a commensurate change in the resin/hardener stoichiometry rather than being directly associated with the presence of the nanofiller. Therefore, this parameter, which usually receives little attention, should be considered when analyzing the performance of epoxy-based nanocomposites.

Silicon nitride $\left(\mathrm{Si}_{3} \mathrm{~N}_{4}\right)$ is an important ceramic material, which has excellent mechanical and electrical properties, such as high breakdown strength, good wear resistance, high thermal conductivity and low thermal expansion coefficient both at room and elevated temperatures [5, 6]. More interestingly, the surface chemistry of $\mathrm{Si}_{3} \mathrm{~N}_{4}$ is characterized by the existence of amine and, to a lesser extent, hydroxyl groups [7-9]. Both of these groups, particularly the amine groups, can react with the epoxy groups in the resin matrix; while the hydroxyl groups usually react only at higher temperatures $\left(>120^{\circ} \mathrm{C}\right)$, they can, nevertheless, act to catalyse amine/epoxy reactions [10]. Therefore, this surface chemistry makes $\mathrm{Si}_{3} \mathrm{~N}_{4}$ intrinsically compatible with an epoxy matrix. In principle, reactions between the amine groups on the silicon nitride surface and the resin's epoxy groups would be expected to be similar to reactions between the latter groups and the amine groups in the hardener. Hence, the inclusion of a $\mathrm{Si}_{3} \mathrm{~N}_{4}$ nanofiller within an epoxy matrix might consume a fraction of the epoxy groups, which would otherwise be expected to crosslink with the hardener and, consequently, may change the effective resin/hardener stoichiometry throughout the whole matrix. The degree of this change in the stoichiometry will depend on the nanofiller surface area, the density of the surface amine groups and the processing conditions, i.e. the mixing procedure, period and temperature.

While detecting a nanofiller stoichiometric influence can help in analyzing the performance of epoxybased nanocomposites, it also offers an opportunity to investigate some of the hypotheses that have been proposed in the literature to account for the behaviour of nanodielectrics. For example, enhanced interactions between the nanoparticles and the epoxy resin in its liquid state should lead to improved dispersion of the as-prepared nanofiller. Nanoparticle dispersion usually imposes a challenge for obtaining actual nanodielectric systems, where the nanoparticles, due to their large specific surface area and surface tension forces, tend to agglomerate, producing a sub-microcomposites [11, 12]. Many researchers have tried to overcome this by treating the nanofiller with matrix-compatible functionalities [13-17]. However, this treatment brings other parameters into play, such as changing the particle surface chemistry and water absorption, and thus, complicates the analysis of the influence of particle dispersion.

Furthermore, many studies have claimed that interactions between nanoparticles and the polymer host matrix result in the formation of an interfacial zone or interphase layer with modified polymeric chain dynamics [18, 19], alignment [20, 21], or morphology [22]. Commonly, such models were proposed to interpret the unexpectedly significant impact of adding a small amount of nanofiller on one or more of the properties of the resulting composites, where two-component effective medium theories cannot explain such effect; some workers have termed this a nanoeffect [23]. For example, the dielectric permittivity of epoxy nanocomposites was found to be lower than that of both the filler and polymer materials in [24-26]. Therefore, the above proposal suggests the formation of an interphase layer and, consequently, defines nanocomposites as a tertiary system that consists of filler, matrix and interphase layer around the particles. The thickness for such an 
interphase has been postulated to range from 5 to $50 \mathrm{~nm}$ for different models, based on the experimental results concerned. Indeed, several simulation studies [27-29] have also indicated the existence of an interphase layer with different chain dynamics around nanoparticles. These investigations have shown that strong attractive polymer/nanoparticle interactions reduce the segmental dynamics near the particles' surface, while repulsive or weak interactions increase segmental dynamics of the interphase layer [28, 29]. Identifying a stoichiometric effect for the addition of $\mathrm{Si}_{3} \mathrm{~N}_{4}$ nanofiller implies the presence of chemical reactions between the epoxy matrix and the nanofiller which, according to the above suggestions, should result in an interphase layer around the nanoparticles where molecular dynamics may be modified. Therefore, this study will investigate the impact of filler/matrix interactions between an epoxy matrix and inherently compatible $\mathrm{Si}_{3} \mathrm{~N}_{4}$ nanoparticles on resin/hardener stoichiometry, particle dispersion and molecular dynamics of silicon nitride epoxy nanocomposites.

\section{Experimental}

\section{Materials}

The silicon nitride nanofiller utilized in this study has a spherical shape with particle size $<50 \mathrm{~nm}$, as specified by the supplier (Sigma Aldrich). The epoxy resin is DER 332, from Sigma Aldrich. This resin is based on diglycidyl ether of bisphenol-A (DGEBA) and has relatively low epoxy equivalent molar mass of $174 \mathrm{~g} / \mathrm{mol}$, which is close to that of pure DGEBA $(170 \mathrm{~g} / \mathrm{mol})$. The hardener used for curing is Jeffamine D230, from Huntsman. This hardener is a polyetheramine hardener with an amine hydrogen equivalent molar mass of 60 $\mathrm{g} / \mathrm{mol}$. Unlike other epoxy systems, i.e. anhydridecured epoxy, where the curing process can proceed via different competitive chemical routes [30-32], a previous study [4] showed that the crosslinking process in this amine-based epoxy system is mainly due to the reaction between the epoxy and amine groups. Therefore, this system was chosen for this investigation as its networking mechanism is simple and any potential variations in the crosslinking density can be directly related to the resin/hardener stoichiometry.
Based on the epoxy and amine equivalent molar masses, the theoretical resin/hardener stoichiometric ratio is 1000:344. As different ratios are employed in this study, a parameter termed the hardener percentage (HP) is used to distinguish between different resin/hardener formulations. This parameter is defined by:

$\mathrm{HP}=\frac{\text { mass of the hardener used }}{\text { hardener stoichoimetric mass }} \%$

where the hardener stoichiometric mass equals 0.344 of the resin mass.

The prepared nanocomposite samples can be divided into two series. The first is filled with $2 \mathrm{wt} \%$ $\mathrm{Si}_{3} \mathrm{~N}_{4}$ at three different HPs, while the other second contains $5 \mathrm{wt} \%$ of nanofiller and employs the same HPs used in the first series. As stated above, the incorporation of $\mathrm{Si}_{3} \mathrm{~N}_{4}$ nanofiller would be expected to increase the overall amine content of the system; therefore, our emphasis was on preparing nanocomposite samples with $\mathrm{HP}<100 \%$ to observe if the added filler will compensate the lack of hardener amine groups. Furthermore, the effect of changing HP on the filled samples was compared with its effect on unfilled samples, which was published in a previous study [4]. In this case, if the $\mathrm{Si}_{3} \mathrm{~N}_{4}$ filler has an impact on the stoichiometry, then a difference between the behaviour of the filled and unfilled samples might be observed and this difference should be proportionally related to the filler loading ratio. The prepared samples can be identified by two parameters, the $\mathrm{Si}_{3} \mathrm{~N}_{4}$ loading ratio and $\mathrm{HP}$, and hence, each sample was given a code which consists of three parts, the first part is common for all the samples and refers to the epoxy resin, the second part refers to the HP used in the samples and the last part refers to the filler loading. For example, E/80H/5SiN refers to an epoxy cured with $\mathrm{HP}=80 \%$ and containing $5 \mathrm{wt} \%$ silicon nitride; $\mathrm{E} / 100 \mathrm{H} / 0$ refers to an epoxy cured with $\mathrm{HP}=100 \%$ (stoichiometric ratio) without any filler; this latter system is taken as a reference for all other samples.

The preparation procedure of the unfilled samples starts with adding the hardener to the resin with the mass ratio required for the specified HP. After that, the hardener was thoroughly mixed with the resin using a magnetic stirrer for $15 \mathrm{~min}$ at room temperature. Subsequently, the mixture was degassed at $35{ }^{\circ} \mathrm{C}$ for $20 \mathrm{~min}$, before casting it into a steel mould for curing. Based on the manufacturer's instructions, 
the curing was performed in a fan oven for $2 \mathrm{~h}$ at $80{ }^{\circ} \mathrm{C}$ followed by $3 \mathrm{~h}$ of post-curing at $125^{\circ} \mathrm{C}$. For the filled samples, the nanofiller was manually mixed with the resin, and then a probe sonicator was used for $45 \mathrm{~min}$ to disperse the particles further. This was followed by heating the particle/resin mixture for $4 \mathrm{~h}$ at $100{ }^{\circ} \mathrm{C}$ so as to stimulate or accelerate any potential interactions between the particles and the resin [25]. After that, the hardener was added and the above epoxy processing procedure was followed. The samples were produced with a thickness of $200 \pm 10 \mu \mathrm{m}$. Before any testing, all samples were stored under vacuum at room temperature for two weeks to remove any water that might be absorbed during the preparation process.

\section{Differential scanning calorimetry}

The crosslink density and the molecular dynamics of the cured samples were examined by characterizing the glass transition process using a Perkin Elmer DSC7 differential scanning calorimeter (DSC). A specimen, $\sim 10 \mathrm{mg}$ in mass, was used to perform two consecutive DSC scans at a heating rate of $10{ }^{\circ} \mathrm{C} /$ min. The obtained DSC traces were normalized with respect to sample mass after subtracting the filler mass, since the filler does not contribute to the glass transition. The first scan was used to eliminate the thermal history of the specimens, and all the data quoted were deduced from the second scan. Three parameters were extracted: the glass transition temperature $\left(T_{\mathrm{g}}\right)$, defined as the temperature at which the rate of change in the heat capacity is maximum; the glass transition width $\left(\Delta T_{\mathrm{g}}\right)$, defined as the temperature range at which the glass transition takes place; the increase in the heat capacity over the glass transition $\left(\Delta C_{\mathrm{p}}\right)$. For each material, the measurement was repeated three times using different specimens in order to analyze the obtained data statistically.

\section{Scanning electron microscopy}

A JEOL JSM-6500F scanning electron microscope (SEM) operating at an accelerating voltage of $15 \mathrm{kV}$ was used to observe particle dispersion inside the epoxy matrix. A cryo-fracturing method was used to expose an internal surface without deforming the polymer during the fracturing process. The exposed surface was sputtered-coated with a thin layer of gold to prevent charge accumulation during SEM examination.

\section{Dielectric spectroscopy}

Dielectric spectroscopy was used to probe the impact of the nanofiller on the polar content and segmental dynamics of the epoxy matrix. Dielectric spectra for all samples were collected over a range of temperatures using a Solartron 1296 dielectric interface along with a Schlumberger SI 1260 impedance/phase gain analyzer. The measurement cell consists of two circular parallel plates with a diameter of $30 \mathrm{~mm}$. Before measurement, the samples were sputtered-coated on both side with gold to improve the contact between the sample and the cell's electrodes.

\section{Results and discussion}

\section{Glass transition and molecular dynamics}

\section{Glass transition temperature}

Variations in the glass transition temperature of the 2 and $5 \mathrm{wt} \%$ filled samples are presented in Fig. 1. $T_{\mathrm{g}}$ of the unfilled samples is also included in this figure, for comparison. For the unfilled epoxy, as demonstrated in [4], $T_{\mathrm{g}}$ is predominantly controlled by the crosslinking density, which is a function of the resin/ hardener stoichiometry. Therefore, decreasing or increasing the HP beyond the stoichiometric percentage $(H P=100 \%)$ leads to a reduction in $T_{g}$. However, as shown in our previous detailed analysis

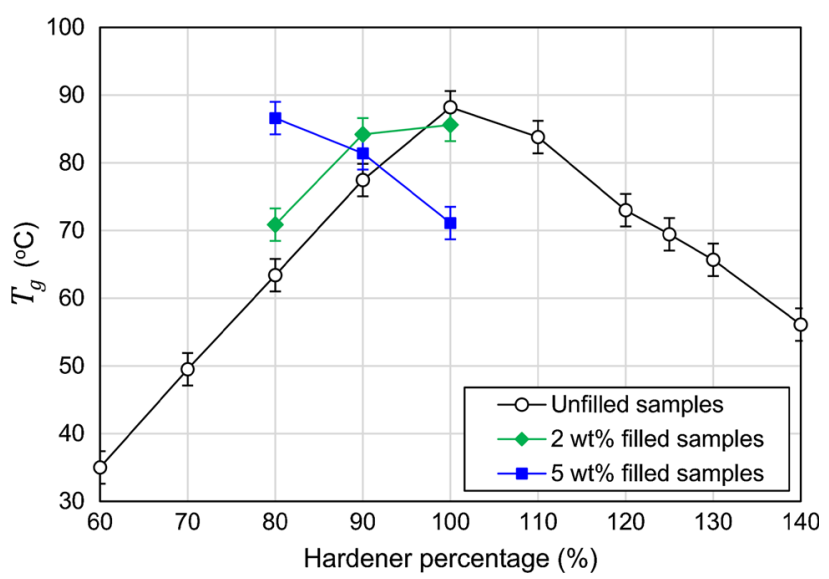

Figure 1 Comparison between $T_{\mathrm{g}}$ of the filled and unfilled epoxy samples. 
of the behaviour of the unfilled system, $T_{\mathrm{g}}$ falls more sharply in system that contain an excess of resin compared with those with an excess of hardener [4]. This, we have proposed, is a consequence of the different ways in which excess epoxide and amine groups influence the network topology that forms, which stems largely from the different functionalities of resin and hardener molecules and the different reaction rates of primary and secondary amine hydrogens. Conversely, both the 2 and $5 \mathrm{wt} \%$ filled samples apparently exhibit different trends. For the $2 \mathrm{wt} \%$ filled samples, reducing the HP to $90 \%$ does not lead to a significant reduction in $T_{g}$; this is, therefore, contrary to the behaviour previously reported for the unfilled counterpart. Reducing the HP further from 90 to $80 \%$ does, however, result in a significant decrease in $T_{\mathrm{g}}$, which is comparable to the change seen in the unfilled samples when HP is similarly reduced by $10 \%$. For the $5 \mathrm{wt} \%$ filled samples, the addition of $\mathrm{Si}_{3} \mathrm{~N}_{4}$ to the stoichiometric formulation results in a significant decrease in $T_{\mathrm{g}}$ when compared with the stoichiometric unfilled sample. Decreasing the HP to $90 \%$ results in a significant increase in $T_{\mathrm{g}}$, and this increase continues when HP decreases to $80 \%$, which is in total contrast to the trend seen in the unfilled samples.

This substantial variation between the effect of changing the stoichiometry on $T_{\mathrm{g}}$ of the filled and unfilled samples might be a physical or chemical consequence of the presence of the $\mathrm{Si}_{3} \mathrm{~N}_{4}$ nanofiller. In the former case, the presence of the nanoparticles may impose a geometric confinement on the polymer molecules, alter the morphology of the matrix or affect the dynamics of the surrounding polymer chains depending on the attraction strength between the polymer and the particle surface [29, 33, 34]. These effects would modify the dynamics or the free volume content of the host polymer, which correspondingly influences $T_{\mathrm{g}}$. For the chemical case, the nanoparticles may chemically interact with the active functionalities in the resin or the hardener, which might then change the crosslinking mechanism or modify the stoichiometry of the active groups in the system. Bignotti [35] examined the effect of changing the resin/hardener ratio on the behaviour of an unfilled and a clay filled amine/epoxy matrix and found that the nanofiller affects neither the crosslinking density, deduced via measuring the elastic modulus, nor the $T_{\mathrm{g}}$ extracted from DSC measurements. Similar findings have been reported by Nguyen [32] for an anhydride epoxy system, where the incorporation of nanosilica affected neither the curing mechanism nor the $T_{\mathrm{g}}$. Yeung [36] recently has observed that the addition of untreated silica had no significant influence on the $T_{\mathrm{g}}$ of the same epoxy matrix considered here. Other studies [37, 38] that considered non-crosslinking polymers have also reported a slight influence on $T_{\mathrm{g}}$, even when the nanoparticles affect the polymer dynamics by inducing a rigid layer, which does not exhibit a glass transition. These findings suggest that as long as the nanoparticles do not chemically interfere with the curing process their physical presence has a marginal impact on $T_{\mathrm{g}}$. Nevertheless, a number of studies have claimed that nanofiller inclusion may increase the free volume in a polymeric matrix [39] or may act to disrupt polymer chain crosslinking $[40,41]$ which, in both cases, leads to a reduction in $T_{\mathrm{g}}$. Conversely, many other experimental [33, 42] and molecular dynamics simulation [27] studies have indicated that strong filler/matrix interactions might reduce the local polymer chain mobility and thus yield a more rigid polymer with higher $T_{\mathrm{g}}$. In the current investigation, if any of the physically induced effects is dominant, then the variations in $T_{\mathrm{g}}$ should be a function of the filler loading not the HP. Clearly this is not applicable, where, for example at $5 \mathrm{wt} \% \mathrm{Si}_{3} \mathrm{~N}_{4}$ loading, the nanofiller reduces $T_{\mathrm{g}}$ by $17{ }^{\circ} \mathrm{C}$ at $\mathrm{HP}$ of $100 \%$ and increases it by $24{ }^{\circ} \mathrm{C}$ at $\mathrm{HP}$ of $80 \%$. (Here, each filled sample was compared with the unfilled sample that has the same HP, as shown in Fig. 1). Therefore, we suggest that the behaviour of $T_{\mathrm{g}}$ is predominantly governed by the stoichiometric effect of the nanofiller. Since the surface of $\mathrm{Si}_{3} \mathrm{~N}_{4}$ is primarily covered by amine groups [7-9], its presence would be expected to increase the effective amine content and, thus, result in an effective HP that is higher than the nominal HP. Indeed, as shown in Fig. 1, at $2 \mathrm{wt} \%$ the particles compensate for part of the amine groups as evinced by lowering the sharp reduction in $T_{\mathrm{g}}$ when the nominal $\mathrm{HP}<100 \%$. Similarly, at $5 \mathrm{wt} \%$ loading, the particles increase the amine content, which produces an amine-rich matrix at a nominal $\mathrm{HP}$ value of $100 \%$ and compensates for a considerable part of the amine content at a nominal $\mathrm{HP}$ of $80 \%$. In order quantitatively to estimate the influence of the filler on the stoichiometry, the HP of the nanocomposites was modified until $T_{\mathrm{g}}$ of the filled samples best matches the $T_{\mathrm{g}}$ of the unfilled samples. According to its definition in Eq. 1, the HP is 
calculated as a ratio of the resin and, therefore, if the amine groups on the surface of the $\mathrm{Si}_{3} \mathrm{~N}_{4}$ particles have consumed a percentage, $x$, of the epoxy groups in the resin, then the effective hardener percentage $\left(\mathrm{HP}_{\text {eff }}\right)$ can be calculated by:

$\mathrm{HP}_{\mathrm{eff}}=\frac{\mathrm{HP}}{(100-x)}$

where HP is the nominal hardener percentage as defined in Eq. 1. Depending on curve fitting between the filled and unfilled samples, it was estimated that $x$ is $\sim 6.5$ and $\sim 18$ for the 2 and $5 \mathrm{wt} \%$ nanocomposite series, respectively. Hence, $2 \mathrm{wt} \%$ of $\mathrm{Si}_{3} \mathrm{~N}_{4}$ reacts with $\sim 6.5 \%$ of the epoxy groups, and $5 \mathrm{wt} \%$ of $\mathrm{Si}_{3} \mathrm{~N}_{4}$ consumes $\sim 18 \%$ of the resin epoxy groups. Figure 2 shows $T_{\mathrm{g}}$ results for all samples as a function of $\mathrm{HP}_{\text {eff, }}$ i.e. after adjusting the HP of the nanocomposite samples according to Eq. 2. Here, it is worth mentioning that $\mathrm{HP}$ and $\mathrm{HP}_{\text {eff }}$ are equivalent for unfilled samples, since $x=0$. Evidently, $T_{\mathrm{g}}$ of filled and unfilled samples exhibits similar trends, and this was for both 2 and $5 \mathrm{wt} \%$ filled samples. The ratio between the resin consumed in the 2 and $5 \mathrm{wt} \%$ filled samples according to the above estimation is $18 / 6.5$ (2.77), which is close to the nominal ratio of $5 / 2 \times 98 / 95$ (2.58) (the factor $95 / 98$ is to account for the resin replaced by the 5 and $2 \mathrm{wt} \%$ filler content). This provides substance to the hypothesis that the added filler reacted with 6.5 and $18 \%$ of the epoxy groups at 2 and $5 \mathrm{wt} \%$, respectively.

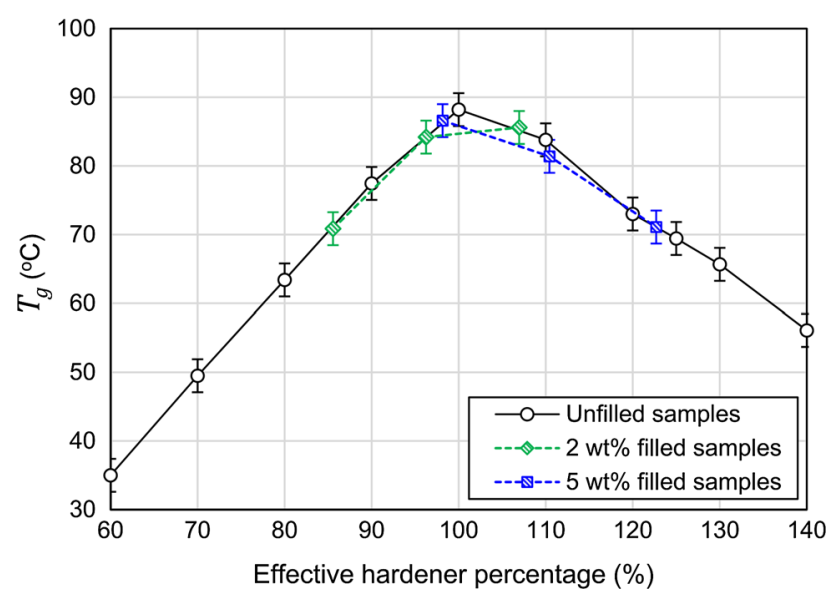

Figure $2 T_{\mathrm{g}}$ of all samples as a function of effective hardener percentage.

\section{Molecular dynamics over the glass transition}

The stoichiometric effect described above provides clear evidence of chemical reaction between the $\mathrm{Si}_{3} \mathrm{~N}_{4}$ particles and the polymer, and, consequently, the next step is to examine how this bonding affects the molecular dynamics over the glass transition. Figure 3a shows the variation of $\Delta C_{p}$ with HP for the $2 \mathrm{wt} \%$ filled, $5 \mathrm{wt} \%$ filled and unfilled samples. The data show that $\Delta C_{p}$ of the nanocomposite samples does not line-up with their counterparts from the unfilled samples. However, when the HP of the nanocomposites is adjusted in the same way as was done above for the $T_{\mathrm{g}}$ results, $\Delta C_{\mathrm{p}}$ for both nanocomposite series aligns well with the results obtained from the unfilled samples (see Fig. 3b). Such agreement reinforces the above assertion about the $\mathrm{Si}_{3} \mathrm{~N}_{4}$ filler's stoichiometric effect and also implies that anchoring of the epoxy molecules on the surface of the particles does not appreciably modify the local
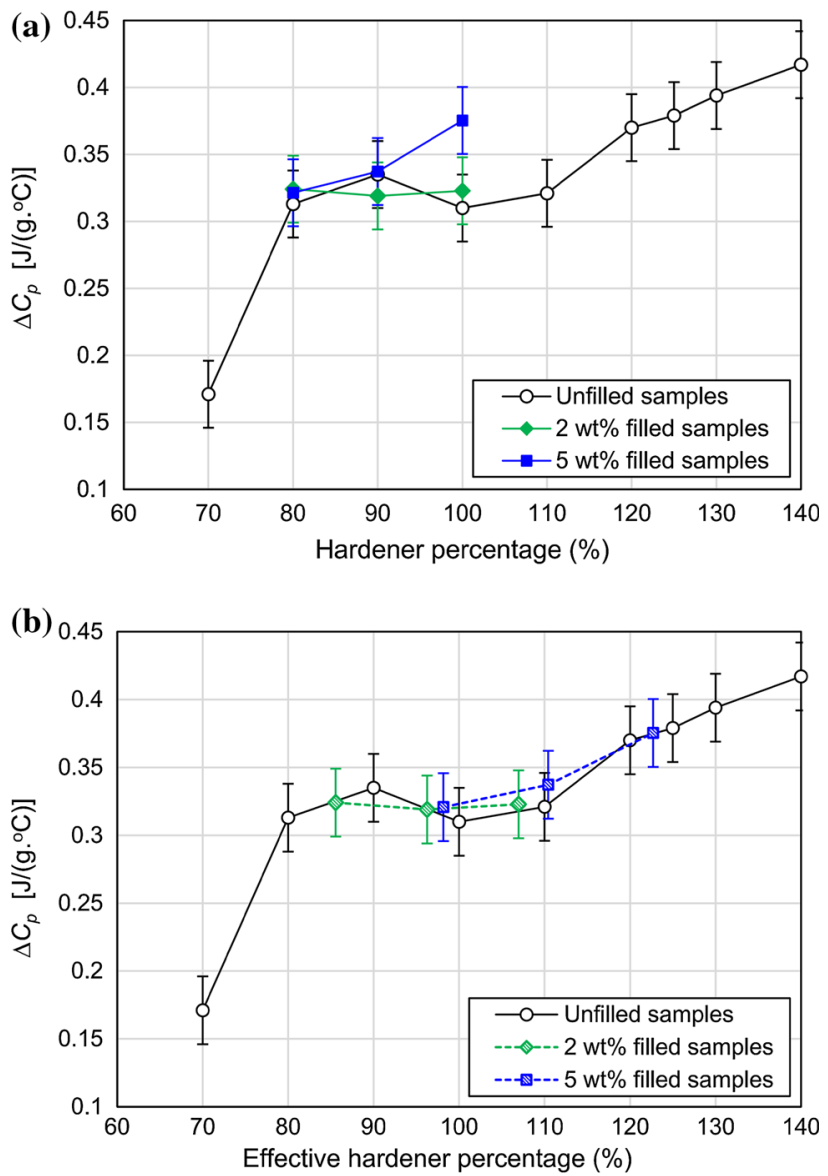

Figure 3 Change in the heat capacity over the glass transition process: $\mathbf{a}$ as a function of nominal hardener percentage and $\mathbf{b}$ as a function of effective hardener percentage. 
segmental dynamics of the epoxy network. Harton [43] and Sargsyan [37] reported that strong hydrogen bonding interactions between silica nanoparticles and polymeric matrices result in an immobilised layer around the particles that does not take part in the glass transition relaxation, such that the $\Delta C_{p}$ of the nanocomposites was found to decrease proportionally with the filler loading. However, in both of these studies, experimental $\Delta C_{\mathrm{p}}$ values obtained from the nanocomposite samples could only be statistically discriminated from $\Delta C_{p}$ values of the corresponding pure polymers when the filler loading was $>20 \mathrm{vol} \%$ (filler size $<25 \mathrm{~nm}$ in both investigations). Consequently, the authors estimated the thickness of the immobilised layer to be $\sim 1 \mathrm{~nm}$ in [43] and $\sim 2 \mathrm{~nm}$ in [37]. Since the maximum filler loading used in our study is much less than $20 \mathrm{vol} \%$, we conclude that the existence of such immobilised layer could not be differentiated from the experimental uncertainties in our data. However, relying on filler size and loading when comparing different studies might be insufficient since there is another factor that needs to be included, particle dispersion, which is difficult to quantify. As an alternative, in this study, we can rely on the estimate that around $18 \%$ of the epoxy groups crosslink with the particle surfaces at $5 \mathrm{wt} \%$ filler loading to explore the possibility of any constrained layer. Assuming that for each attached epoxy group, the dynamics of its corresponding DGEBA molecule is confined and forms an immobilised segment. This implies that the thickness of the postulated immobilised layer corresponds to the length of one DGEBA molecule or $2.6 \mathrm{~nm}$ [44], which is in the range of the thicknesses proposed by Harton [43] and Sargsyan [37]. This would result in an immobilised mass fraction that equals $18 \times 2 \times 1000 / 1344$ or $\sim 27 \%$ of the whole polymeric matrix, assuming that each DGEBA molecule can react with the particles with only one of its two epoxy groups and considering the mass of the hardener at $\mathrm{HP}=100 \%$. A mass fraction of $27 \%$ is well out of the experimental uncertainties shown in Fig. 3, and, therefore, it should be detectable. Since this is not the case, the thickness of any possible immobilised layer should be less than one DGEBA molecule length. Based on $95 \%$ uncertainty boundaries, which is around $\pm 7.5 \%$ of the average of $\Delta C_{p}$, an immobilized layer that represents more than $7.5 \%$ of the sample polymer mass should be experimentally detectable. Consequently, the thickness of any immobilized layer should be $<1 \mathrm{~nm}$. Investigating the chemical structure of DGBEA shows that the epoxy group is connected to the rest of the molecule through an ether functional group. This connection is structurally flexible as the conformation of $\mathrm{C}-\mathrm{O}-\mathrm{C}$ has low energy and steric barriers. The existence of such a flexible bond might limit the effect of any dynamic confinement, due to the bonding to the particle, to the few atoms next to the epoxy/particle bond, and, therefore, this will bring the thickness of any affected layer to a few angstroms. Consequently, in this particular system, the structure of the DGBEA molecules may reduce the impact of polymer/particle interactions on the segmental dynamics of the polymer layer surrounding the nanoparticles. However, different impact on the polymer dynamics could occur for different polymer chain structures, as reported elsewhere [37, 43, 45].

\section{Network homogeneity}

Instead of forming a completely rigid layer that does not contribute to the glass transition, other studies have claimed that strong filler/polymer interactions cause a broadening of the glass transition to higher temperatures [45-47] or result in additional glass transition steps at different temperature [45-48]. Therefore, the polymer/filler attachment might cause a restriction for the segmental dynamics of the surrounding polymer, and this effect gradually decreases with the distance from the particle surface. Such an effect would reduce the homogeneity of the polymeric matrix and, as a result, increase the glass transition width $\left(\Delta T_{\mathrm{g}}\right)$. Alternatively, the affected polymeric fraction may relax at a distinct temperature range, which would be reflected as a second glass transition step in the DSC traces. To investigate these possibilities, Fig. 4 presents representative DSC traces obtained from a number of different systems, while Fig. 5 compares $\Delta T_{\mathrm{g}}$ of the nanocomposite samples (after adjusting their HP) with $\Delta T_{\mathrm{g}}$ of the unfilled samples. Both of these figures do not show any sign of significant glass transition broadening or additional glass transition processes in the nanocomposite samples. This again suggests that the thickness of any affected polymeric layer is too small to result in a measurable influence on the cooperative dynamics (i.e. at the glass transition) of this particular epoxy system. 


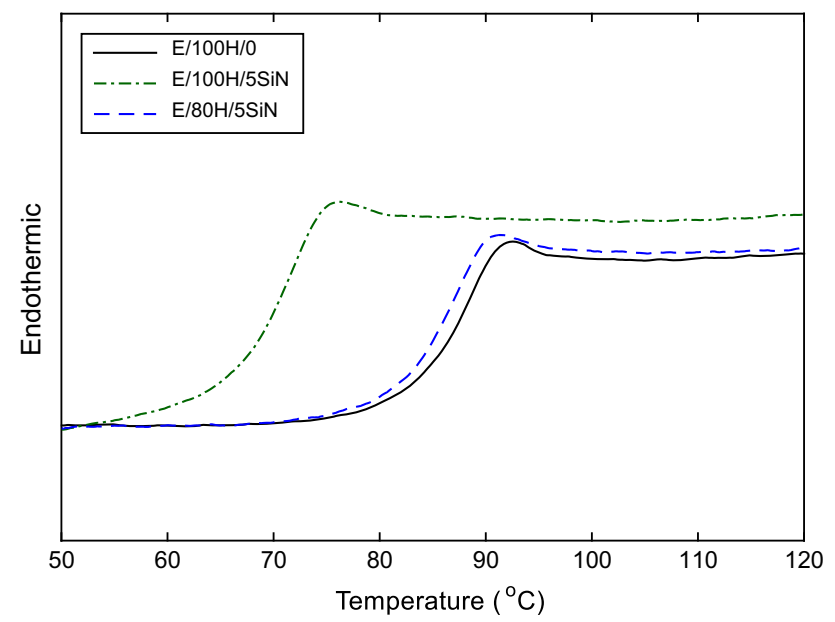

Figure 4 DSC traces obtained from the reference sample and some of the filled samples.

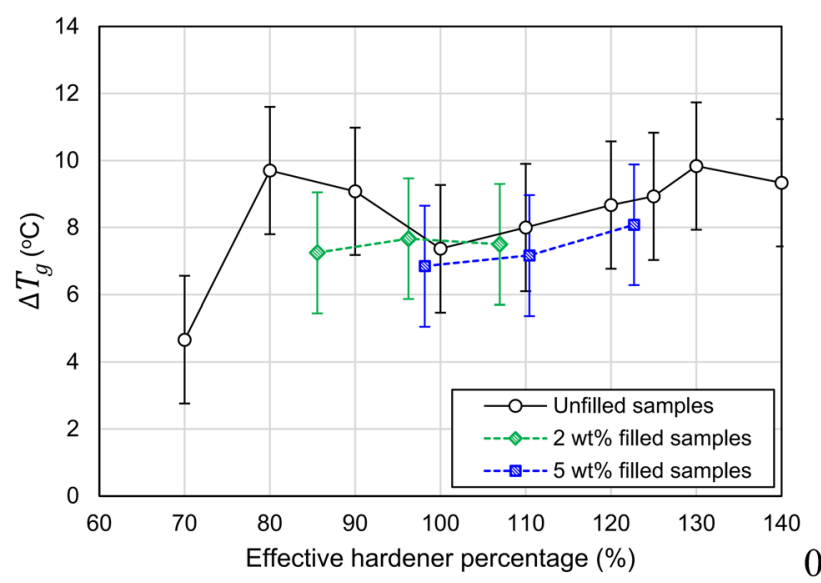

Figure 5 Glass transition width as a function of effective hardener percentage for all samples.

\section{Dielectric spectra}

Dielectric spectra obtained from the two nanocomposite series along with the reference sample are presented in Figs. 6 and 7. A broad $\beta$ relaxation process that peaks at $\sim 4 \times 10^{4} \mathrm{~Hz}$ and extends from $1 \mathrm{MHz}$ down to low frequencies around $10 \mathrm{~Hz}$ is pronounced in all samples. However, its strength varies from one sample to another. This relaxation is generally attributed to the rotation of the hydroxyether groups that are generated due to the crosslinking reaction between the epoxy and amine groups [49-51], and its strength should therefore be related to the crosslinking density of the epoxy network. For the $2 \mathrm{wt} \%$ filled nanocomposites, the strength of the $\beta$ relaxation for samples E/ $100 \mathrm{H} /$ $2 \mathrm{SiN}$ and $\mathrm{E} / 90 \mathrm{H} / 2 \mathrm{SiN}$ is not significantly different

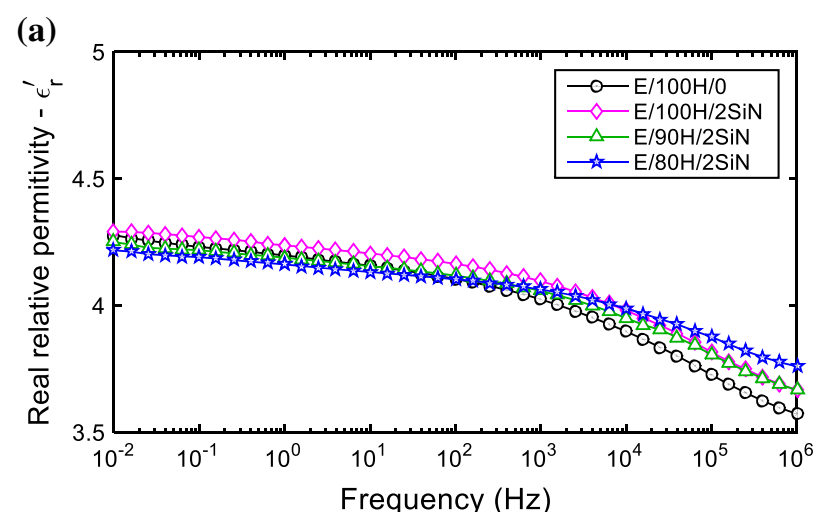

(b)

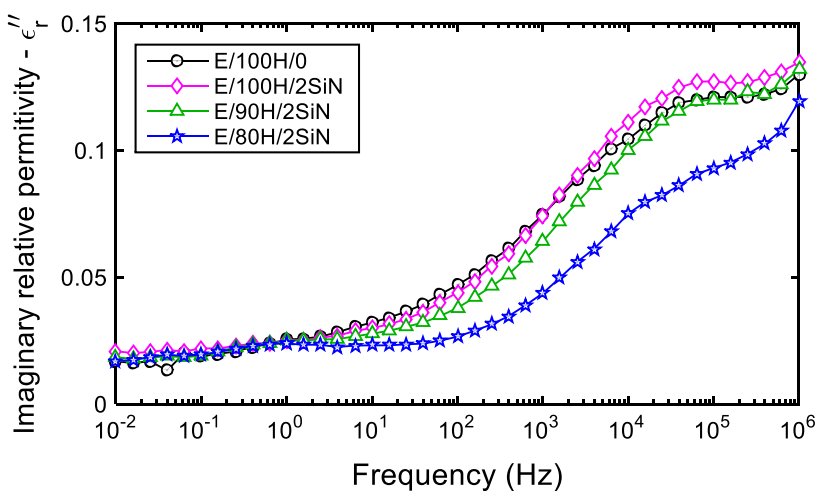

Figure 6 Dielectric spectra for $2 \mathrm{wt} \%$ filled nanocomposites compared with the reference sample, a real permittivity and b imaginary permittivity.

from that of the reference sample since the crosslinking density in these samples, deduced from $T_{\mathrm{g}}$ is not markedly affected. For sample E/80H/ $2 \mathrm{SiN}$, Fig. $6 \mathrm{~b}$ indicates that the strength of the $\beta$ relaxation is noticeably reduced and, consequently, the real part of the relative permittivity $\left(\epsilon_{\mathrm{r}}^{\prime}\right)$ is increased at high frequencies. This behaviour was also seen in unfilled samples when HP is less than $100 \%$, as reported in [4]. Part of the $\beta$ relaxation reduction is attributed to the lower concentration of hydroxyether groups (as evinced by the lower $T_{\mathrm{g}}$ ), and another part is related to its partial displacement to higher frequencies, which results in the uplift in the values of $\epsilon_{\mathrm{r}}^{\prime}$ at high frequencies [4]. For the $5 \mathrm{wt} \%$ filled samples, the strength of the $\beta$ relaxation increases progressively as the nominal HP is reduced from 100 to $80 \%$, which correlates with the behaviour of $T_{g}$ of these samples and also implies that the effective crosslinking density and $\mathrm{HP}_{\text {eff }}$ are anti-correlated with the nominal HP. Furthermore, such smooth variations in the $\beta$ relaxation are in accordance with its behaviour of amine-rich unfilled 
(a)

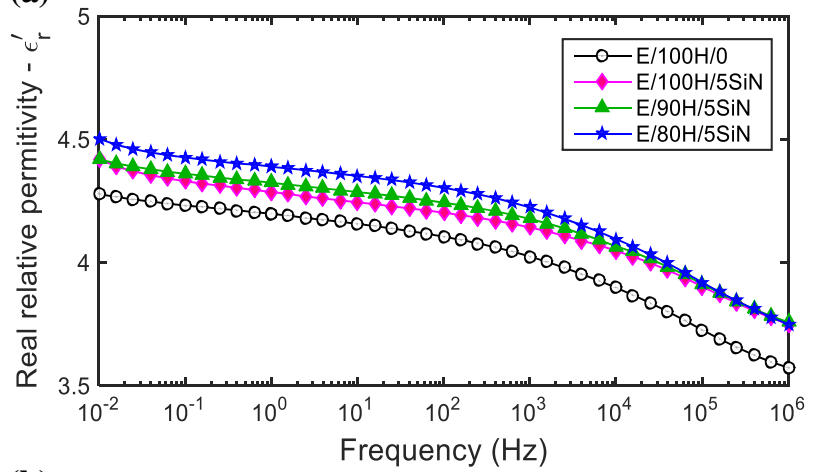

(b)

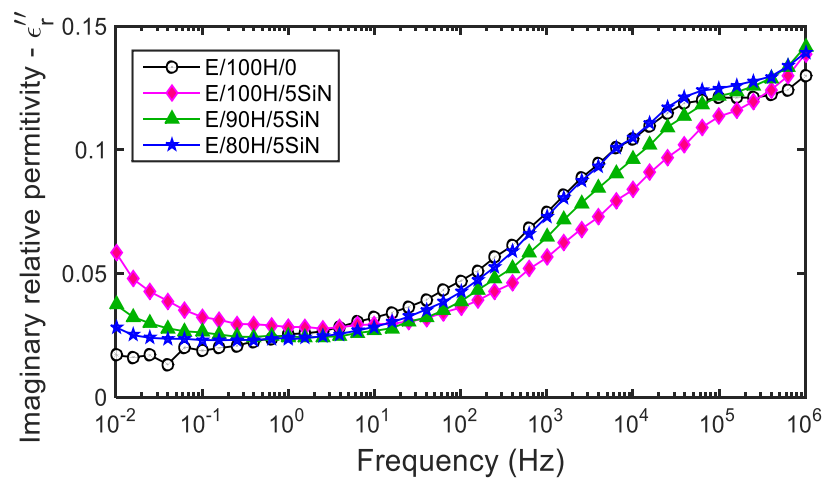

Figure 7 Dielectric spectra for $5 \mathrm{wt} \%$ filled nanocomposites compared with the reference sample, a real permittivity and b imaginary permittivity.

samples [4]. Therefore, these variations in the $\beta$ relaxation lead to the same conclusions as derived from the DSC results concerning the crosslinking density and the stoichiometric influence of the $\mathrm{Si}_{3} \mathrm{~N}_{4}$ filler. To consolidate further the above description of the $\beta$ relaxation, its strength was estimated by evaluating the difference in $\epsilon_{\mathrm{r}}^{\prime}$ between $1 \mathrm{MHz}$ and $10 \mathrm{~Hz}$ for each sample and the results are presented in Fig. 8 as a function of HP for the unfilled samples and as a function of $\mathrm{HP}_{\text {eff }}$ (based on $\mathrm{T}_{\mathrm{g}}$ analysis) for the nanocomposites. This approach of evaluating the relaxation strength, rather than depending on absolute values of $\epsilon_{\mathrm{r}}^{\prime \prime}$, has the advantage of eliminating some of the experimental errors. Although the data in Fig. 8 could be influenced by the experimental errors as could be seen by the overlapping of the error bars, the data reveal that both the unfilled and filled epoxy matrices exhibit analogous $\beta$ relaxation with respect to their nominal and effective HP, respectively.

Another feature that appeared only in the spectra of the $5 \mathrm{wt} \%$ filled series at frequencies $<1 \mathrm{~Hz}$ is that $\epsilon_{r}^{\prime \prime} \quad$ starts increasing gradually with decreasing

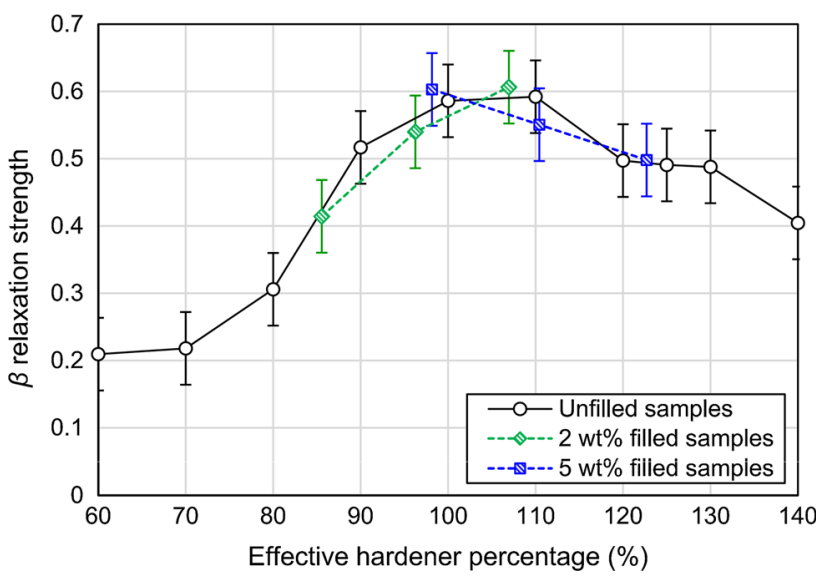

Figure 8 Strength of the $\beta$ relaxation for all samples as a function of HP for the unfilled samples and as a function of $\mathrm{HP}_{\text {eff }}$ (based on $T_{\mathrm{g}}$ analysis) for the nanocomposite samples.

frequency (Fig. 7). This increase in $\epsilon_{r}^{\prime \prime}$ at low frequencies might be due to a higher DC conductivity of these samples or might be the high frequency tail of a relaxation that peaks at a frequency below our accessible range. Many studies have shown that the addition of nanoparticles imparts a new mid- or lowfrequency relaxation peak that moves to higher frequencies with increasing temperature $[36,52]$ or with absorbed water [53-55]. Related to the materials considered here, Hosier [56] has recently reported that the addition of $\mathrm{Si}_{3} \mathrm{~N}_{4}$ nanoparticles into a polyethylene matrix causes a new relaxation that shifts to higher frequency with higher water uptake; Yeung [36] has also observed a similar feature that peaks at higher frequencies for higher temperatures, for the same epoxy matrix when filled with nanosilica. This phenomenon is attributed to the polar functionalities on the nanoparticles' surface and the water molecules which associate with these groups. Consequently, if the behaviour observed here is due to nanoparticlerelated relaxation, it should be a function of nanoparticle content. While this may rationalize the absence of this feature in the $2 \mathrm{wt} \%$ filled series, it is not consistent with the variations seen between the different $5 \mathrm{wt} \%$ filled samples (which have the same particle content), and, thereby, this eliminates the attribution to particle-related relaxation. Nevertheless, to corroborate the above conclusion, dielectric spectra of sample E/100/5SiN were obtained at higher temperatures (Fig. 9a) and after exposing it to ambient condition, which allows it to absorb water (Fig. 9b). As is evident from these spectra, in none of these cases does this feature develop into a relaxation 
(a)

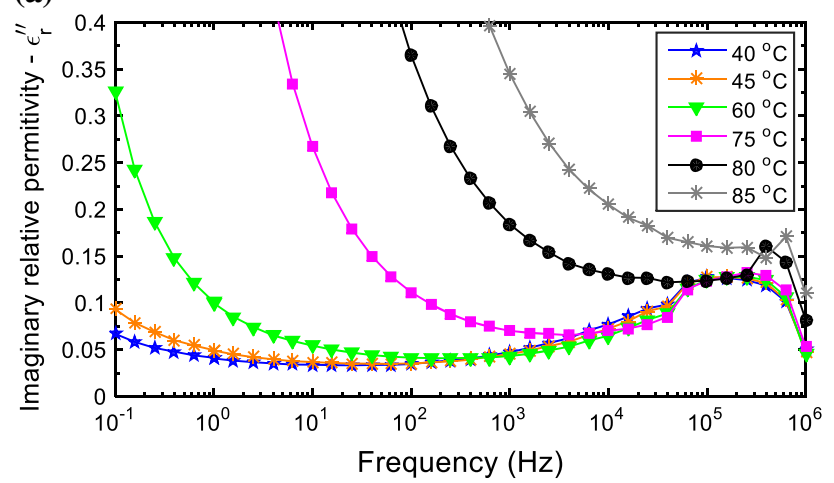

(b)

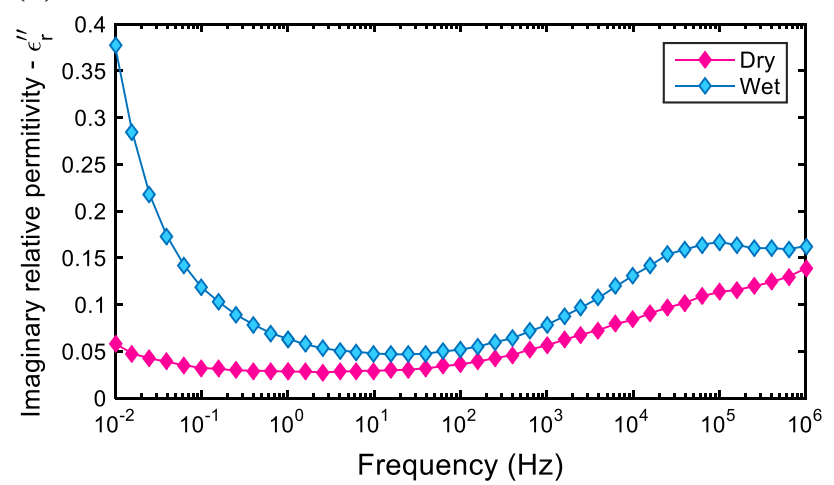

Figure 9 Imaginary relative permittivity of sample E/100H/5SiN at: $\mathbf{a}$ different temperatures, and $\mathbf{b}$ different water content.

peak that moves to higher frequencies. Instead, $\epsilon_{\mathrm{r}}^{\prime \prime}$ continues further to increase at low frequencies, which is a typical behaviour that results from higher DC conductivity at higher temperature [4] or higher water content [57]. Therefore, we suggest that this behaviour is related to increased DC conductivity in these samples. As shown in [4], the DC conductivity of unfilled samples is proportionally correlated with $\mathrm{HP}$, which matches the values of $\epsilon_{\mathrm{r}}^{\prime \prime}$ at low frequencies in Fig. $7 \mathrm{~b}$, where sample $\mathrm{E} / 100 / 5 \mathrm{SiN}$ has the highest $\mathrm{HP}$ and, accordingly, it should have the highest DC conductivity and $\epsilon_{\mathrm{r}}^{\prime \prime}$ at low frequencies. Another inference relating to the above discussion is that the absence of any particle-related relaxation in the systems investigated here implies that most of the polar content on the surface of the particles is removed. This implies that most of the particles' amine groups have reacted with the resin's epoxy groups, which results in hydroxyether groups, as is the case when the resin reacts with the hardener. This again reinforces the effect of $\mathrm{Si}_{3} \mathrm{~N}_{4}$ filler on the stoichiometry.

Regarding variations seen in the absolute values of $\epsilon_{\mathrm{r}}^{\prime}$, notwithstanding that most of these variations are within experimental uncertainties, one trend can be observed. That is, within each nanocomposite series, $\epsilon_{\mathrm{r}}^{\prime}$ decreases in proportion to the reduction in the $\beta$ relaxation strength. For example, at $10 \mathrm{~Hz}, \epsilon_{\mathrm{r}}^{\prime}$ slightly decreases from sample E/100/2SiN to sample E/80/ 2SiN, where the value of $\epsilon_{\mathrm{r}}^{\prime}$ is even less than that in the reference sample. This trend can be explained by the decline in hydroxyether group concentration (polar content), which is a consequence of the reduction in the crosslinking density.

In conclusion, apart from the feature caused by the apparent increase in DC conductivity, the dielectric spectra of the filled samples and their unfilled counterparts are analogous, when the filler stoichiometric effect is taken into account. That is, the nanofiller does not appreciably affect the polar content or the dynamics of the already existing polar groups. Rationally, since the DSC data analysis demonstrated that the filler does not markedly modify the cooperative $\alpha$ relaxation at the glass transition, it is expected that the more localized $\beta$ relaxation is not affected as well. Even in studies that have reported a nanofiller effect on the glass transition, the smaller scale $\beta$ relaxation was not perturbed [37, 43]. On the other hand, other studies [24, 25], which investigated the effect of nanofiller on dielectric response of epoxy matrices, claimed that nanofiller inclusion can lead to $\epsilon_{\mathrm{r}}^{\prime}$ values that are lower than the $\epsilon_{\mathrm{r}}^{\prime}$ of both the filler and the host matrix. These studies justified this reduction by postulating a layer of restricted polymer chain mobility around the nanoparticles; however, no experimental exploration has been attempted to validate this proposition. As discussed above, changing the resin/hardener stoichiometry results in a reduction in the $\beta$ relaxation strength and, to a lesser extent, $\epsilon_{\mathrm{r}}^{\prime}$. Therefore, the reduction in $\epsilon_{\mathrm{r}}^{\prime}$ seen in these studies might be related to nanofiller-induced stoichiometry variations. Although, in both studies the behaviour of $T_{\mathrm{g}}$ was not reported to confirm any stoichiometric effect, yet, in both of these studies, there are signs that may support this rationalization. In [24], the reduction in $\epsilon_{\mathrm{r}}^{\prime}$ was accompanied by a reduction in the $\beta$ relaxation, which may imply a reduction in crosslinking density. In the other study [25], the $\epsilon_{\mathrm{r}}^{\prime}$ reduction was more pronounced in the samples prepared following a specific route that included mixing the particles with the resin for $12 \mathrm{~h}$. In this preparation route, any 
possible reaction between the particles and the components of the epoxy matrix is maximized, due to the long period of mixing, which may affect the stoichiometry of the network.

\section{Nanoparticle dispersion}

Figure 10 presents representative SEM images obtained from unfilled and filled samples. The image of the unfilled sample, Fig. 10a, shows a typical featureless one phase morphology, in accordance with the amorphous single phase structure of epoxy networks. Similar SEM images have been reported elsewhere [32, 58]. For the filled samples, Fig. 10b shows well-dispersed nanoparticles throughout the network. The higher magnification image shown in Fig. 10c indicates that individual particles, of a size commensurate with that quoted by the supplier $(<50 \mathrm{~nm})$, are uniformly distributed within the matrix. Nonetheless, Fig. 10c also shows the presence of occasional small agglomerations, less than $\sim 300 \mathrm{~nm}$ in size, where a few particles are clustered beside each other. Compared with some other nanofiller types, the dispersion state shown here for $\mathrm{Si}_{3} \mathrm{~N}_{4}$ is much better. For example, the introduction of untreated silica, which is polar and, thus, can be considered compatible with the polar epoxy matrix, has been reported to produce particle agglomerations that can reach the microscale size $[59,60]$. Even for silica which was treated with a silane coupling agent terminated with an epoxy group, microscale particle agglomerations have been observed [36]. Furthermore, the same $\mathrm{Si}_{3} \mathrm{~N}_{4}$ nanofiller investigated in this study showed an inferior dispersion state when it was added into polyethylene [55] or polypropylene [61] matrices. Therefore, the superior particle dispersion in the systems investigated here should be a consequence of the chemical reaction between the surface amine groups of the $\mathrm{Si}_{3} \mathrm{~N}_{4}$ and the epoxy groups in the resin, which represents stronger interactions than that provided by Van der Waal attraction or the hydrogen bonding between compatible or polar functionalities on the particle surface and in the polymer base material.
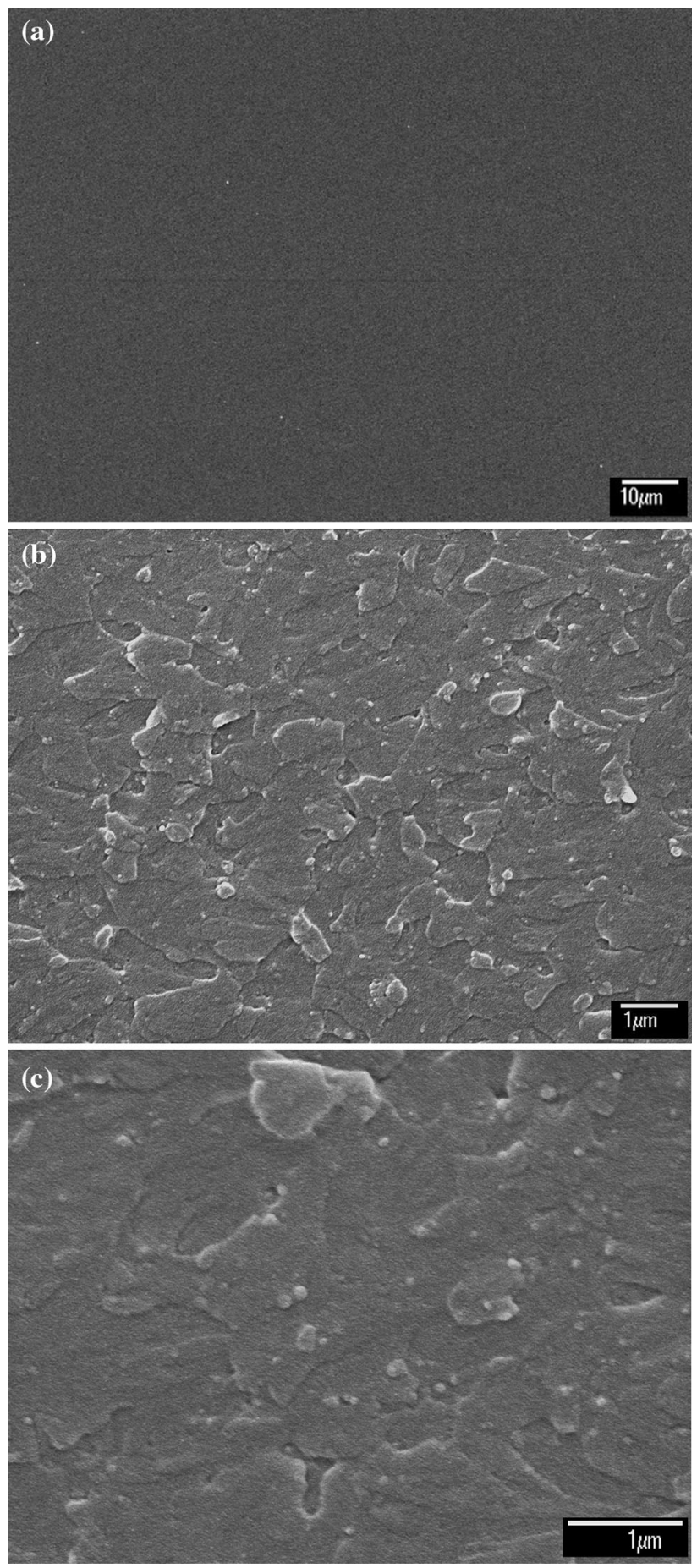

Figure 10 Representative SEM images for a unfilled epoxy, b $5 \mathrm{wt} \% \mathrm{Si}_{3} \mathrm{~N}_{4}$ filled epoxy, and c $5 \mathrm{wt} \% \mathrm{Si}_{3} \mathrm{~N}_{4}$ filled epoxy (higher magnification). 


\section{Conclusions}

The incorporation of nanofillers, which have large specific surface area covered by different chemical groups, into a thermosetting matrix can significantly affect its curing process directly by reacting with the active groups in the resin and/or the hardener. In the amine/epoxy system considered here, the silicon nitride nanofiller, with amine groups on its surface, can react with a considerable fraction of the epoxy groups in the system and, consequently, affect the resin/hardener stoichiometry and the resulting network structure. At $2 \mathrm{wt} \%$ of nanofiller, it was estimated that the nanofiller contains amine groups equivalent to around $6.5 \%$ of the epoxy groups, whereas at $5 \mathrm{wt} \%$, the filler reacted with $\sim 18 \%$ of the resin's epoxy groups. However, the resulting covalent bonding between the particles and the polymer matrix does not appreciably influence the polymeric segmental dynamics of the investigated system, neither at a cooperative nor at segmental scale, as revealed by DSC and dielectric spectroscopy analysis, respectively. On the other hand, strong interactions between the nanofiller and the resin lead to systems in which the nanoparticles are well dispersed within the epoxy matrix.

\section{Compliance with ethical standards}

Conflict of interest The authors declare that they have no conflict of interest.

\section{Open Access}

This article is distributed under the terms of the Creative Commons Attribution 4.0 International License (http://creativecommons.org/licenses/by/ $4.0 /$ ), which permits unrestricted use, distribution, and reproduction in any medium, provided you give appropriate credit to the original author(s) and the source, provide a link to the Creative Commons license, and indicate if changes were made.

\section{References}

[1] Li Y, Zhang B, Pan X (2008) Preparation and characterization of PMMA-kaolinite intercalation composites. Compos Sci Technol 68(9):1954-1961. https://doi.org/10.1016/j. compscitech.2007.04.003
[2] Miwa Y, Drews AR, Schlick S (2006) Detection of the direct effect of clay on polymer dynamics: the case of spin-labeled poly(methyl acrylate)/clay nanocomposites studied by ESR, XRD, and DSC. Macromolecules 39(9):3304-3311. https:// doi.org/10.1021/ma0600963

[3] Virtanen S, Krentz TM, Nelson JK, Schadler LS, Bell M, Benicewicz B, Hillborg H, Zhao S (2014) Dielectric breakdown strength of epoxy bimodal-polymer-brush-grafted core functionalized silica nanocomposites. IEEE Trans Dielectr Electr Insul 21(2):563-570. https://doi.org/10.1109/tdei. 2014.004415

[4] Alhabill FN, Ayoob R, Andritsch T, Vaughan AS (2017) Effect of resin/hardener stoichiometry on electrical behavior of epoxy networks. IEEE Trans Dielectr Electr Insul (in press)

[5] Cheng G, Qian J, Tang Z, Ding G, Zhu J (2015) Dispersion stability of Si3N4 nano-particles modified by gammamethacryloxypropyl trimethoxy silane (MAPTMS) in organic solvent. Ceram Int 41(1):1879-1884. https://doi.org/ 10.1016/j.ceramint.2014.09.013

[6] Cerovic LS, Milonjic SK, Bahloul-Hourlier D, Doucey B (2002) Surface properties of silicon nitride powders. Colloids Surf A 197(1-3):147-156. https://doi.org/10.1016/ s0927-7757(01)00863-9

[7] Busca G, Lorenzelli V, Baraton MI, Quintard P, Marchand R (1986) FT-IR characterization of silicon nitride Si3N4 and silicon oxynitride SI2ON2 surfaces. J Mol Struct 143:525-528. https://doi.org/10.1016/0022-2860(86)853169

[8] Tai YL, Qian JS, Miao JB, Xia R, Zhang YC, Yang ZG (2012) Preparation and characterization of Si3N4/SBR nanocomposites with high performance. Mater Des 34:522-527. https://doi.org/10.1016/j.matdes.2011.05.002

[9] Li YL, Liang Y, Zheng F, Xiao K, Hu ZQ, Shun T (1995) Fourier transformation infrared investigation of surface oxidation of ultrafine Si3N4 powders. J Mater Sci Lett 14(10):713-715

[10] Baller J, Thomassey M, Ziehmer M, Sanctuary R (2011) The catalytic influence of alumina nanoparticles on epoxy curing. Thermochim Acta 517(1-2):34-39. https://doi.org/10.1016/ j.tca.2011.01.029

[11] Supova M, Martynkova GS, Barabaszova K (2011) Effect of nanofillers dispersion in polymer matrices: a review. Sci Adv Mater 3(1):1-25. https://doi.org/10.1166/sam.2011.1136

[12] Starr FW, Douglas JF, Glotzer SC (2003) Origin of particle clustering in a simulated polymer nanocomposite and its impact on rheology. J Chem Phys 119(3):1777-1788. https:// doi.org/10.1063/1.1580099

[13] Sekhavat Pour Z, Ghaemy M (2014) Fabrication and characterization of superparamagnetic nanocomposites based on 
epoxy resin and surface-modified $\gamma$-Fe2O3 by epoxide functionalization. J Mater Sci 49(12):4191-4201. https://doi. org/10.1007/s10853-014-8114-6

[14] Ribeiro H, Silva WM, Rodrigues M-TF, Neves JC, Paniago R, Fantini C, Calado HDR, Seara LM, Silva GG (2013) Glass transition improvement in epoxy/graphene composites. J Mater Sci 48(22):7883-7892. https://doi.org/10.1007/ s10853-013-7478-3

[15] He L, Chuang W, Zihao G, Haoran W, Yuxuan Z, Rui H (2016) Zongren P (2016) Effects of silane coupling agents on the electrical properties of silica/epoxy nanocomposites. IEEE Int Conf Dielectr (ICD) 2:1036-1039. https://doi.org/ 10.1109/ICD.2016.7547795

[16] Zhang L, Zhou YX, Cui XY, Sha YC, Le TH, Ye Q, Tian JH (2014) Effect of nanoparticle surface modification on breakdown and space charge behavior of XLPE/SiO2 nanocomposites. IEEE Trans Dielectr Electr Insul 21(4):1554-1564. https://doi.org/10.1109/tdei.2014.004361

[17] Roy M, Nelson JK, MacCrone RK, Schadler LS (2007) Candidate mechanisms controlling the electrical characteristics of silica/XLPE nanodielectrics. J Mater Sci 42(11):3789-3799. https://doi.org/10.1007/s10853-0060413-0

[18] Tanaka T, Kozako M, Fuse N, Ohki Y (2005) Proposal of a multi-core model for polymer nanocomposite dielectrics. IEEE Trans Dielectr Electr Insul 12(4):669-681. https://doi. org/10.1109/tdei.2005.1511092

[19] Li K, Li Y, Lian QS, Cheng J, Zhang JY (2016) Influence of cross-linking density on the structure and properties of the interphase within supported ultrathin epoxy films. J Mater Sci 51(19):9019-9030. https://doi.org/10.1007/s10853-0160155-6

[20] Andritsch T, Kochetov R, Morshuis PHF, Smit JJ (2011) Proposal of the polymer chain alignment model. In: Annual report conference on electrical insulation and dielectric phenomena, 16-19 Oct 2011. pp 624-627. https://doi.org/ 10.1109/CEIDP.2011.6232734

[21] Tsekmes IA, Kochetov R, Morshuis PHF, Smit JJ (2014) A unified model for the permittivity and thermal conductivity of epoxy based composites. J Phys D Appl Phys 47(41):415502. https://doi.org/10.1088/0022-3727/47/41/ 415502

[22] Raetzke S, Kindersberger J (2010) Role of interphase on the resistance to high-voltage arcing, on tracking and erosion of silicone/SiO2 nanocomposites. IEEE Trans Dielectr Electr Insul 17(2):607-614. https://doi.org/10.1109/TDEI.2010. 5448118

[23] Praeger M, Andritsch T, Swingler SG, Vaughan AS (2014) A simple theoretical model for the bulk properties of nanocomposite materials. In: Paper presented at the 2014
IEEE conference on electrical insulation and dielectric phenomena

[24] Kochetov R, Andritsch T, Morshuis PHF, Smit JJ (2012) Anomalous behaviour of the dielectric spectroscopy response of nanocomposites. IEEE Trans Dielectr Electr Insul 19(1):107-117. https://doi.org/10.1109/TDEI.2012. 6148508

[25] Kurimoto M, Okubo H, Kato K, Hanai M, Hoshina Y, Takei M, Hayakawa N (2010) Permittivity characteristics of epoxy/ alumina nanocomposite with high particle dispersibility by combining ultrasonic wave and centrifugal force. IEEE Trans Dielectr Electr Insul 17(4):1268-1275. https://doi.org/ 10.1109/TDEI.2010.5539699

[26] Zhou W, Yu D (2013) Fabrication, thermal, and dielectric properties of self-passivated Al/epoxy nanocomposites. J Mater Sci 48(22):7960-7968. https://doi.org/10.1007/ s10853-013-7606-0

[27] Starr FW, Schrøder TB, Glotzer SC (2002) Molecular dynamics simulation of a polymer melt with a nanoscopic particle. Macromolecules 35(11):4481-4492. https://doi.org/ 10.1021/ma010626p

[28] Desai T, Keblinski P, Kumar SK (2005) Molecular dynamics simulations of polymer transport in nanocomposites. J Chem Phys 122(13):134910. https://doi.org/10.1063/1.1874852

[29] Simone N, Emmanouil G, Nicholas BT (2017) Glass transition of polymers in bulk, confined geometries, and near interfaces. Rep Prog Phys 80(3):036602. https://doi.org/10. 1088/1361-6633/aa5284

[30] Fedtke M, Domaratius F (1986) Curing of epoxide-resins by anhydrides of dicarboxylic-acids: model reactions. Polym Bull 15(1):13-19

[31] Matejka L, Lovy J, Pokorny S, Bouchal K, Dusek K (1983) Curing epoxy-resins with anhydrides: model reactions and reaction-mechanism. J Polym Sci Part a: Polym Chem 21(10):2873-2885. https://doi.org/10.1002/pol.1983. 170211003

[32] Nguyen VT, Vaughan AS, Lewin PL, Krivda A (2015) The effect of resin stoichiometry and nanoparticle addition on epoxy/silica nanodielectrics. IEEE Trans Dielectr Electr Insul 22(2):895-905. https://doi.org/10.1109/tdei.2014. 004785

[33] Rittigstein P, Torkelson JM (2006) Polymer-nanoparticle interfacial interactions in polymer nanocomposites: confinement effects on glass transition temperature and suppression of physical aging. J Polym Sci Part B: Polym Phys 44(20):2935-2943. https://doi.org/10.1002/polb.20925

[34] Bansal A, Yang HC, Li CZ, Cho KW, Benicewicz BC, Kumar SK, Schadler LS (2005) Quantitative equivalence between polymer nanocomposites and thin polymer films. Nat Mater 4(9):693-698. https://doi.org/10.1038/nmat1447 
[35] Bignotti F, Pandini S, Baldi F, De Santis R (2011) Effect of the resin/hardener ratio on curing, structure and glass transition temperature of nanofilled epoxies. Polym Compos 32(7):1034-1048. https://doi.org/10.1002/pc.21120

[36] Yeung C, Vaughan AS (2016) On the effect of nanoparticle surface chemistry on the electrical characteristics of epoxybased nanocomposites. Polymers 8(4):126. https://doi.org/ 10.3390/polym8040126

[37] Sargsyan A, Tonoyan A, Davtyan S, Schick C (2007) The amount of immobilized polymer in PMMA $\mathrm{SiO} 2$ nanocomposites determined from calorimetric data. Eur Polym J 43(8):3113-3127. https://doi.org/10.1016/j.eur polymj.2007.05.011

[38] Moll J, Kumar SK (2012) Glass transitions in highly attractive highly filled polymer nanocomposites. Macromolecules 45(2):1131-1135. https://doi.org/10.1021/ ma202218x

[39] Siddabattuni S, Schuman TP, Dogan F (2013) Dielectric properties of polymer-particle nanocomposites influenced by electronic nature of filler surfaces. ACS Appl Mater Interfaces 5(6):1917-1927. https://doi.org/10.1021/am3030239

[40] Preghenella M, Pegoretti A, Migliaresi C (2005) Thermomechanical characterization of fumed silica-epoxy nanocomposites. Polymer 46(26):12065-12072. https://doi. org/10.1016/j.polymer.2005.10.098

[41] Umboh MK, Adachi T, Oishi K, Higuchi M, Major Z (2013) Mechanical properties of nano-silica particulate-reinforced epoxy composites considered in terms of crosslinking effect in matrix resins. J Mater Sci 48(15):5148-5156. https://doi. org/10.1007/s10853-013-7300-2

[42] Blum FD, Lin W-Y, Porter CE (2003) Dynamics of adsorbed poly(methyl acrylate) and poly(methyl methacrylate) on silica. Colloid Polym Sci 281(3):197-202. https://doi.org/10. 1007/s00396-002-0795-8

[43] Harton SE, Kumar SK, Yang HC, Koga T, Hicks K, Lee E, Mijovic J, Liu M, Vallery RS, Gidley DW (2010) Immobilized polymer layers on spherical nanoparticles. Macromolecules 43(7):3415-3421. https://doi.org/10.1021/ ma902484d

[44] Prasad A, Grover T, Basu S (2010) Coarse-grained molecular dynamics simulation of cross-linking of DGEBA epoxy resin and estimation of the adhesive strength. Int J Eng Sci Technol 2(4):17-30

[45] Holt AP, Griffin PJ, Bocharova V, Agapov AL, Imel AE, Dadmun MD, Sangoro JR, Sokolov AP (2014) Dynamics at the polymer/nanoparticle interface in poly(2-vinylpyridine)/ silica nanocomposites. Macromolecules 47(5):1837-1843. https://doi.org/10.1021/ma5000317

[46] Bershtein V, Gun'ko V, Egorova L, Guzenko N, Pakhlov E, Ryzhov V, Zarko V (2009) Well-defined silica core- poly(vinyl pyrrolidone) shell nanoparticles: interactions and multi-modal glass transition dynamics at interfaces. Polymer 50(3):860-871. https://doi.org/10.1016/j.polymer.2008.12. 024

[47] Chen L, Zheng K, Tian XY, Hu K, Wang RX, Liu C, Li Y, Cui P (2010) Double glass transitions and interfacial immobilized layer in in-situ-synthesized poly(vinyl alcohol)/ silica nanocomposites. Macromolecules 43(2):1076-1082. https://doi.org/10.1021/ma901267s

[48] Chouhan DK, Rath SK, Kumar A, Alegaonkar PS, Kumar S, Harikrishnan G, Patro TU (2015) Structure-reinforcement correlation and chain dynamics in graphene oxide and Laponite-filled epoxy nanocomposites. J Mater Sci 50(22):7458-7472. https://doi.org/10.1007/s10853-0159305-5

[49] Jordan C, Galy J, Pascault JP (1992) Measurement of the extent of reaction of an epoxy-cycloaliphatic amine system and influence of the extent of reaction on its dynamic and static mechanical-properties. J Appl Polym Sci 46(5):859-871. https://doi.org/10.1002/app.1992.070460513

[50] Soles CL, Yee AF (2000) A discussion of the molecular mechanisms of moisture transport in epoxy resins. J Polym Sci Part B: Polym Phys 38(5):792-802. https://doi.org/10. 1002/(sici)1099-0488(20000301)38:5<792:aid-polb16>3.0. $\mathrm{co} ; 2-\mathrm{h}$

[51] Kosmidou TV, Vatalis AS, Delides CG, Logakis E, Pissis P, Papanicolaou GC (2008) Structural, mechanical and electrical characterization of epoxy-amine/carbon black nanocomposites. Express Polym Lett 2(5):364-372. https:// doi.org/10.3144/expresspolymlett.2008.43

[52] Panaitescu DM, Vuluga Z, Notingher PV, Nicolae C (2013) The effect of poly styrene-b-(ethylene-co-butylene)-b-styrene on dielectric, thermal, and morphological characteristics of polypropylene/silica nanocomposites. Polym Eng Sci 53(10):2081-2092. https://doi.org/10.1002/pen.23475

[53] Hui L, Schadler LS, Nelson JK (2013) The influence of moisture on the electrical properties of crosslinked polyethylene/silica nanocomposites. IEEE Trans Dielectr Electr Insul 20(2):641-653. https://doi.org/10.1109/TDEI.2013. 6508768

[54] Couderc H, Frechette M, Savoie S, Reading M, Vaughan AS (2012) Dielectric and thermal properties of boron nitride and silica epoxy composites. In: Conference record of the 2012 IEEE international symposium on electrical insulation (Isei), pp 64-68

[55] Hosier IL, Praeger M, Vaughan AS, Swingler SG (2015) Electrical properties of polymer nano-composites based on oxide and nitride fillers. IEEE Electr Insul Conf, pp 438-441. https://doi.org/10.1109/ICACACT.2014.7223515 
[56] Hosier IL, Praeger M, Vaughan AS, Swingler SG (2017) The effects of water on the dielectric properties of silicon-based nanocomposites. IEEE Trans Nanotechnol 16(2):169-179. https://doi.org/10.1109/TNANO.2016.2642819

[57] Alhabill FN, Andritsch T, Vaughan AS (2017) Moisture absorption behavior in silicon nitride epoxy nanocomposites. IEEE electrical insulation conference (EIC), 2011, pp 471-474. https://doi.org/10.1109/EIC.2017.8004638

[58] Shukla DK, Parameswaran V (2007) Epoxy composites with $200 \mathrm{~nm}$ thick alumina platelets as reinforcements. J Mater Sci 42(15):5964-5972. https://doi.org/10.1007/s10853-0061110-8

[59] Qiang D, He M, Chen G, Andritsch T (2015) Influence of nano-SiO2 and $\mathrm{BN}$ on space charge and $\mathrm{AC} / \mathrm{DC}$ performance of epoxy nanocomposites. In: IEEE electrical insulation conference, pp 492-495. https://doi.org/10.1109/ ICACACT.2014.7223519

[60] Marx P, Wanner A, Zhang Z, Jin H, Tsekmes I-A, Smit J, Kern W, Wiesbrock F (2017) Effect of interfacial polarization and water absorption on the dielectric properties of epoxy-nanocomposites. Polymers 9(6):195

[61] Xu GC, Wang J, Ji XL, Xiong JY, Li F (2007) Effect of nanosilicon nitride on the mechanical and electric properties of polypropylene nanocomposite. J Compos Mater 41(18):2213-2223. https://doi.org/10.1177/002199830707 4185 